\title{
Vida e circunstâncias, estágio supervisionado na Licenciatura em Matemática e isolamento social: constituindo alternativas
}

\section{Life and circumstances, supervised internship in Mathematics and social isolation: constituting alternatives}

\author{
DWanderleya Nara Gonçalves Costa \\ Doutora em Educação \\ Universidade Federal de Mato Grosso - UFMT \\ Pontal do Araguaia, Mato Grosso - Brasil \\ wannara@ufmt.br
}

Resumo: A investigação, metodologicamente referenciada na pesquisa-ação, está vinculada ao conjunto de pesquisas voltadas para a formação inicial docente. Problematizando os processos que ocorrem nos estágios, o estudo questiona como as adaptações efetuadas durante o isolamento social podem contribuir para reconfigurar as práticas a serem constituídas na Licenciatura em Matemática. Inicialmente, o texto traça o panorama de exclusão digital sofrida por acadêmicos que moram em áreas rurais. Salienta que vários cursos de licenciatura têm apresentado dificuldades na adoção de estratégias para que a Educação Ambiental se realize e para que a Educação no Campo seja discutida. Finalmente, descreve e analisa um trabalho de extensão universitária realizado num assentamento rural do MST, no centro-oeste brasileiro. Então, conclui que atividades extensionistas que ocorram no estágio ou no cumprimento da Lei $n^{\circ}$. 13.005/2014 podem constituir-se como estratégias para se garantir a necessária atenção à temas rotineiramente excluídos dos currículos das licenciaturas.

Palavras-chave: Formação docente. Ensino de Matemática. Educação Ambiental. Educação do Campo. Extensão Universitária.

\begin{abstract}
The investigation, methodologically referenced in action research, is linked to the set of research aimed at initial teacher education. Questioning the processes that occur in the internships, the study askshow the adaptations made during social isolation can contribute to reconfigure the practices to be constituted in the Mathematics Degree. Initially, the text traces the panorama of digital exclusion suffered by academics who live in rural areas. Then, he stresses that several courses have presented difficulties in adopting strategies for Environmental Education to take place. Finally, it describes and analyzes a university extension work carried out in a rural settlement of the MST, in central-western of Brazil. Then, it concludes that extension activities that occur in the internship or in compliance with Law no. 13.005/2014 can constitute strategies for digital inclusion and Environmental Education.
\end{abstract}

Keywords: Teacher training. Math teaching. Environmental education. Field education. University Extension. 


\section{Introdução}

No cotidiano de boa parte da população mundial, consolidou-se o uso de computador, notebook, telefone celular e tablet como instrumentos que permitem não só a comunicação, o acesso à informação e ao conhecimento, mas também como ferramentas de trabalho. Em vista disto, ainda no século passado, em relatório à Organização das Nações Unidas para Educação, Ciência e Cultura (UNESCO), foi recomendado o uso de tecnologias digitais para desenvolver a colaboração entre quem ensina e quem aprende, priorizando a educação permanente dos sujeitos e a formação continuada de professores, dentre outros (DELORS et al,1998).

Ainda assim, salvo exceções, a escola pública brasileira pouco avançou no sentido de fomentar a cultura digital, quer de professores, quer de estudantes. Não foi garantida conectividade gratuita e de boa qualidade em grande parte das escolas, nem a qualificação do corpo docente para uso educacional das Tecnologias Digitais de Informação e Comunicação (TDIC). Nos ressentiríamos disto durante a interrupção das atividades presenciais de ensino nas escolas e nas universidades devido à pandemia de COVID-19, visto que tal interrupção fez. com que se recorresse intensamente à intermediação das TDIC para dar continuidade ao processo de educaşão formal.

Reconhecendo que o afastamento do ambiente escolar de cerca de 850 milhões de crianças e de jovens configura-se uma crise educacional sem precedentes, a UNESCO estabeleceu um grupo de trabalho com a missão de proporcionar assessoria e assistência técnica aos governos que buscassem oferecer educação aos estudantes fora da escola durante a pandemia. A seu turno, o Fundo das Nações Unidas para a Infância (UNICEF) também procurou mobilizar-se para apoiar a continuidade do aprendizado escolar no período de isolamento social devido à COVID-19, tendo Bernt Aasen, diretor regional do UNICEF para a América Latina e o Caribe, asseverado que:

\footnotetext{
Para continuar seus estudos em casa, todas as ferramentas e todos os canais disponíveis deverão ser utilizados, seja por rádio, televisão, internet ou telefone celular. Só conseguiremos enfrentar esse desafio por meio de um esforço conjunto de governos, setor privado, pais, mães e crianças e adolescentes. (AASEN adup BASTOS e BOSCARIOLI, 2020, sem paginação).
}

$\mathrm{Na}$ afirmação acima, observemos, tal como fizeram Bastos e Boscarioli (2020), que os professores não são citados como partícipes do esforço conjunto. Contudo, a esses profissionais têm sido atribuída a tarefa de colocarem-se na linha de frente para que a continuidade dos estudos formais se efetive em tempos de isolamento social, cabendo-lhes se reinventar e utilizar as TDIC de modo não apenas a promover o aprendizado, mas também a manter o vínculo dos estudantes com a comunidade escolar. Nesse contexto, ressaltam os autores, veem-se "professores angustiados, tentando produzir conteúdos em formatos até então não [ou pouco] explorados, sem 
a certeza de sua efetividade e se alcançarão todo o seu alunado" (BASTOS e BOSCARIOLI, 2020, sem paginação). Assim, a lacuna na formação docente representada pela carência de oportunidades que favoreçam o uso eficiente das tecnologias digitais para o ensino ficou mais evidente, levandonos a refletir sobre vidas, circunstâncias e formação de professores.

Em particular, grande parte dos estudantes que recebemos no curso de Licenciatura em Matemática do Campus do Araguaia, da Universidade Federal de Mato Grosso (CUA/UFMT), possui uma cultura digital exígua. Em vista disso, empregamos algumas estratégias para que os estudantes do curso estejam envolvidos em atividades que buscam conduzir à reflexão sobre o uso ético, seguro e responsável das TDIC; atividades que os levem a pesquisar, utilizar e manipular ferramentas e conteúdos digitais, bem como a compreender a colaboração das TDIC na comunicação, na aprendizagem dos estudantes, nos processos avaliativos e na gestão da sala de aula, dentre outros.

Contudo, isso não ocorre de modo sistemático, até porque, devido à redução das verbas destinadas às universidades federais, o Laboratório de Educação Matemática da instituição não conta com equipamentos necessários à utilização escolar das TDIC. Isto tem implicado no uso de notebooks, tablets e telefones celulares pessoais dos professores e dos estudantes - quando esses os possuem. Entretanto, pelo menos no Brasil, milhões de pessoas não têm acesso às tecnologias digitais, o que os torna partícipes do processo nomeado de exclusão digital e que se manifesta com maior evidência nas áreas rurais, onde reside parte dos estudantes do curso.

Segundo Fornasier e Scarantti (2017), mais de oitenta por cento da população brasileira que reside no campo não possui computador conectado à internet; dentre esses, encontram-se parte dos acadêmicos da Licenciatura em Matemática do CUA/UFMT. Entretanto, com a reorganização das atividades educacionais devido à pandemia, elevaram-se as práticas mediadas pelas tecnologias digitais da informação e da comunicação nas disciplinas do curso oferecidas em 2020.

De modo especial, quando a Universidade Federal de Mato Grosso (UFMT) adotou a chamada 'flexibilização educacional' para oferta das disciplinas por meio das TDIC, em caráter excepcional e temporário, durante o período de distanciamento social, a exclusão digital de alguns estudantes ficou mais evidente. Vimo-nos diante da necessidade de criar estratégias para que estudantes moradores em áreas rurais também pudessem dar continuidade às atividades das disciplinas curriculares, inclusive dos estágios supervisionados.

No curso de Licenciatura em Matemática do Campus do Araguaia da UFMT, as cargas horárias das três disciplinas de estágio obrigatório são estruturadas de modo que $50 \%$ está voltada para a docência e a outra metade é dividida igualmente entre pesquisa e extensão. É mister informar 
ainda que, no período de flexibilização educacional, apenas as atividades dos dois últimos eixos foram cumpridas, pois a docência deve ocorrer de modo presencial em escolas de educação básica. Para a orientação aos estudantes matriculados na disciplina de Estágio Supervisionado III, a única do núcleo de estágio oferecida no período, foram adotadas as estratégias de encontros coletivos, tanto síncronos, quanto assíncronos; também utilizamos comunicação pessoal via e-mail e WhatsApp. Nesse contexto, as adaptações que ocorreram na disciplina de Estágio Supervisionado III nos levaram a inquerir:

(De que modo) as adaptações efetuadas no estágio supervisionado durante o período de isolamento social devido à pandemia podem contribuir para reconfigurar as práticas a serem constituídas na licenciatura em matemática no pós-pandemia?

Para abordar a questão, nossa escolha metodológica recaiu sobre a pesquisa-ação, reconhecida por André (2010) como uma forma adequada de investigação das problemáticas da formação docente, juntamente com várias modalidades de pesquisas colaborativas que "vêm sendo progressivamente apontadas como estratégias adequadas de formação do professor pesquisador e de produção compartilhada de conhecimentos" (p. 275). Entretanto, como o conceito de pesquisaação é polissêmico, assumimos, a partir de Dionne (2007), que a pesquisa-ação é uma prática que associa pesquisadores e atores, constituindo-se, em paralelo, como uma estratégia de ação para modificar uma dada situação e também como uma estratégia de pesquisa para adquirir um conhecimento sistemático sobre a situação identificada.

No texto em tela, inicialmente, resgatamos alguns estudos sobre o estágio supervisionado e discorremos sobre modificações nos modos de se efetivarem algumas das atividades da disciplina de Estágio Supervisionado III no curso de Licenciatura em Matemática do Campus Universitário do Araguaia, da UFMT. Ressaltamos que as mudanças foram provocadas pelas circunstâncias impostas pelo isolamento social durante a pandemia, em confluência como o modo de vida dos estudantes, aliadas à preocupação da Universidade em garantir oportunidades iguais a todos os acadêmicos. Em seguida, como um contributo para se chegar a uma resposta para a questão de pesquisa, contextualizamos e analisamos um dos projetos que vêm sendo executados na disciplina e, finalmente, apontamos possíveis desdobramentos/sugestões para a formação inicial de professores de matemática.

\section{O estágio supervisionado na formação docente}

A investigação abordada nesse texto se insere no conjunto de pesquisas voltadas para a formação docente; um campo que, sobretudo nas duas últimas décadas, tem-se colocado em 
constante movimento, com referenciais teóricos e metodológicos frequentemente revistos e ampliados. Nesse contexto, Pimenta (2006) considera que é fundamental problematizar os processos que ocorrem nos estágios, enquanto instâncias formativas para a docência. A autora pontua que o estágio supervisionado é uma atividade que tem uma dimensão teórico-prática que corrobora para efetuar a formação ampla e densa necessária à elaboração de conhecimentos específicos para o exercício da profissão docente.

Espera-se que o estágio supervisionado promova o estreitamento das relações entre a universidade e as escolas da educação básica a partir de uma perspectiva que contribua para o desenvolvimento da autonomia, da criatividade, do espírito de pesquisa, da cooperação e do pensamento reflexivo dos futuros professores [(PIMENTA e LIMA, 2004); (PIMENTA, 2006); (MELO e PIMENTA, 2019)]. Nesse sentido, o estágio pode auxiliar na construção da identidade docente, ao ampliar e aprofundar o conhecimento pedagógico e acerca da práxis educativa [(PIMENTA e LIMA, 2019); (COSTA, 2020)]. Essa concepção acerca do estágio abriga a ideia de que o licenciando que tenha experiências variadas e ricas vivências tende a uma prática pedagógica mais consistente e segura, pois as múltiplas experiências influenciarão suas atitudes, sugerindo recursos e posturas e orientando possibilidades de ação no ambiente escolar. A partir dessa concepção, dentre as atividades de estágio, a pesquisa e a extensão também encontram espaço.

Em concordância com esse modo de entender o estágio supervisionado, no curso no qual atuamos, as disciplinas da área estão organizadas em torno de atividades de ensino, de pesquisa e de extensão. Em particular, assumimos que os projetos de extensão são construtores de saberes para a docência e conectores entre o ensino e a pesquisa. Nessa condição, desde 2009, os projetos de extensão fazem parte das disciplinas de estágio supervisionado, ocupando vinte e cinco por cento da carga horária destas.

No desenvolvimento do estágio durante o isolamento social devido à pandemia de COVID-19, os projetos de extensão priorizaram a realização de trabalhos remotos. A elaboração dos planos de trabalho se deu a partir da análise conjunta, pela professora orientadora e cada licenciando e licencianda, das circunstâncias e dos questionamentos/preocupações pessoais, bem como dos possíveis impactos formativos a serem atingidos com o desenvolvimento das ações. Um dos objetivos dos projetos colocados em prática pelos estagiários é contribuir com a formação do professor reflexivo; algo que compreende o ato de pesquisa, de indagação, de dúvida. Implica ainda a construção da competência para administrar a própria aprendizagem, de tornar-se "capaz de definir objetivos pessoais, organizar e gerir tempos e espaços, auto avaliar e avaliar processos, controlar ritmos, conteúdos e tarefas" (CARVALHO e COSTA, 2015, p. 158). 
Notadamente, devido à interrupção de orientações presenciais do estágio, tornou-se fundamental adotar atividades mais flexíveis, que permitissem aos professores em formação inicial controlar ritmos e tarefas, bem como evitar o deslocamento daqueles que moram em áreas rurais. Também assumimos que os estudantes das áreas rurais teriam maior dificuldade de acesso às ferramentas de comunicação. Ainda assim, algumas das características das ações extensionistas que ocorrem presencialmente como parte do estágio do curso foram mantidas, isto é:

\begin{abstract}
[...] tomamos a problematização como ponto de partida, o rigor do saber científico e a integração entre ensino-pesquisa-extensão como norteadores, a contextualização como recurso integrador e a realidade da Educação Básica como cenário para a concretização da aprendizagem dos licenciandos, sensibilizando-os para o comprometimento com as transformações sociais necessárias à educação do País. (COSTA, 2019)
\end{abstract}

As atividades rotineiramente executadas nos projetos de extensão são: oferecimento de minicursos e de oficinas a estudantes do Ensino Fundamental e Médio, assistência pedagógica a instituições e a órgãos comunitários e educacionais, apoio na implantação de laboratório de ensino de matemática, organização e/ou apoio na realização de olimpíadas de matemática, feiras, seminários, palestras, fóruns, gincanas, mostras culturais e assistência a pessoas com dificuldades de aprendizagem. Porém, com a determinação do isolamento social e a interrupção das aulas presenciais, surgiram projetos que assumiram diferentes configurações. Em comum, os novos projetos buscaram estimular a autonomia docente na elaboração de materiais didáticos e ainda levar os licenciandos a refletir sobre o uso de diferentes opções de recursos didáticos para o ensino da matemática. Nessa conjuntura, têm sido produzidos podcasts, vídeocasts, jogos, sequências didáticas e outros.

Contudo, nesse momento da investigação, são tomados como focos de nossa atenção as escolhas, as posturas e as atividades que têm permeado a elaboração e a execução do projeto extensionista de estágio de uma estudante moradora em um assentamento rural criado a partir do Movimento dos Trabalhadores sem Terra (MST). Para acesso às aulas e às orientações do estágio, ela conta apenas com um computador emprestado de um membro da família e com um telefone celular com acesso limitado à uma internet geralmente instável. Para preservar sua identidade, tomando como inspiração a mitologia romana, neste trabalho, a estudante será referida como Ceres, em lembrança à deusa protetora da agricultura, da colheita e dos grãos. 


\section{Educação Matemática, Educação do Campo e Educação Ambiental: explorando confluências no estágio}

No Brasil, a institucionalização da Educação Ambiental (EA) aconteceu em 1973, com a criação da Secretaria Especial do Meio Ambiente, e se consolidou na Política Nacional do Meio Ambiente, Lei 6.938/1981, na Constituição Federal do Brasil de 1988, na Política Nacional de Educação Ambiental, Lei 9.795, sancionada em 1999, na qual está prevista “ampla participação da escola, da universidade e de organizações não-governamentais na formulação e execução de programas e atividades vinculadas à educação ambiental”. Ainda nas palavras da Lei:

\footnotetext{
Art. 10. A educação ambiental será desenvolvida como uma prática educativa integrada, contínua e permanente em todos os níveis e modalidades do ensino formal.

$\int 1$ o A educação ambiental não deve ser implantada como disciplina específica no currículo de ensino. (...)

Art. 11. A dimensão ambiental deve constar dos currículos de formação de professores, em todos os níveis e em todas as disciplinas. (BRASIL, 1999)
}

A Educação Ambiental também se ancora legalmente nas Diretrizes Curriculares Nacionais para Educação Ambiental (DCNEA), na Resolução nº 2 de 15 de junho de 2012, Parecer CNE/CP no 14/2012 e, mais recentemente, na Resolução CNE/CP N 2, de 20 de dezembro de 2019 (Base Nacional Comum para a formação inicial de professores da educação básica - BNC-Formação). Essa última coloca como competência 7 :

\footnotetext{
Desenvolver argumentos com base em fatos, dados e informações científicas para formular, negociar e defender ideias, pontos de vista e decisões comuns, que respeitem e promovam os direitos humanos, a consciência socioambiental, o consumo responsável em âmbito local, regional e global, com posicionamento ético em relação ao cuidado de si mesmo, dos outros e do planeta. (BRASIL, 2019)
}

Contudo, não se tem garantido a efetividade da Educação Ambiental na formação de professores, visto que são relativamente poucos os Projetos Pedagógicos de Cursos (PPC) que tratam em profundidade das temáticas ambientais e sociais, privilegiando os conteúdos específicos dos cursos, como asseguram Cortes Júnior e Fernandez (2016) e Silva e Baldin (2019). Com efeito, no curso de Licenciatura em Matemática do CUA/UFMT não houve especial preocupação com a inserção da temática ambiental no currículo.

Também cabe assumir que o curso empreende pouca atenção à Educação do Campo, seguindo a tendência assumida em outras licenciaturas de excluir "da discussão, da problematização e da construção de metodologias, os contextos e grupos minoritários, tais como as iniciativas de educação popular, os movimentos sociais, o meio rural, entre outros” (RIBEIRO e MARIN, 2009, p. 79). Contudo, abordar a temática continua sendo necessário, pois embora a Licenciatura em 
Educação do Campo exista no País desde 2006, o número de cursos existentes não é capaz de suprir a demanda da população do campo.

Arroyo, Caldart e Molina (2004, p.176) esclarecem que:

A educação do campo, tratada como educação rural na legislação brasileira, tem um significado que incorpora os espaços da floresta, da pecuária, das minas e da agricultura, mas os ultrapassa ao acolher em si os espaços pesqueiros, caiçaras, ribeirinhos e extrativistas. O campo, nesse sentido, mais do que um perímetro não urbano, é um campo de possibilidades que dinamizam a ligação dos seres humanos com a própria produção das condições da existência social e com as realizações da sociedade humana.

Nesse contexto, tem sido enfatizada a importância de que as escolas do campo não assumam o perfil de uma educação ruralista, idealizada pelas elites para a formação de trabalhadores braçais agrícolas alienados do sistema produtivo, social e cultural. Busca-se, ao contrário, uma escola que atenda os interesses e respeite as particularidades das populações do campo.

$\mathrm{Na}$ Educação Matemática, a Etnomatemática proposta por D’Ambrosio (2002) tem oferecido uma proposta teórico-metodológica que reconhece e valoriza os diferentes saberes e fazeres matemáticos presentes nas práticas sociais. Com tais características, as pesquisas em etnomatemática oferecem subsídios para o desenvolvimento de uma educação matemática escolar que abrange não só o conhecimento científico, mas também explora saberes matemáticos específicos, particulares, locais. Nessa condição, a etnomatemática tornou-se importante para a elaboração de propostas que sejam adequadas à educação do campo.

A partir do aporte teórico da etnomatemática, como parte dos seus trabalhos na disciplina de Estágio Supervisionado III, a estudante Ceres tem realizado uma pesquisa que objetiva: a) conhecer as propostas da Educação Matemática para as escolas do campo, b) narrar a história do ensino de matemática na escola do assentamento situado em Doverlândia/GO e c) identificar os conhecimentos, procedimentos e cálculos utilizados no assentamento durante os processos de plantio, cultivo, colheita e comercialização de mandiocas. Também é objetivo da estudante que, no desenvolvimento de atividades de extensão universitária, sejam gerados e oferecidos à escola local materiais didáticos que contribuam para relacionar esses saberes matemáticos — usados no dia-adia de produção e comercialização de mandiocas - ao conhecimento formal presente no currículo de Matemática. Metodologicamente, Ceres tem feito uso de pesquisa participante. Têm utilizado, como técnicas de coleta de dados, entrevistas com um agricultor produtor de mandiocas e relato autobiográfico.

O olhar para o cotidiano do produtor de mandiocas tem evidenciado o uso de conhecimentos relativos à medidas de comprimento, ao cálculo de área, à estimativa de peso, dentre outros a serem explorados na escola. Ao falar com a estagiária, o sujeito da pesquisa empreende 
um trânsito constante entre unidades de medidas não convencionais - da etnomatemática rural — e unidades de medidas convencionais, do Sistema Internacional de Unidades (SI). Quanto aos conhecimentos etnomatemáticos detectados, podemos citar a "chave" e o "passo grande", medidas de comprimento que correspondem a, aproximadamente, $10 \mathrm{~cm}$ e a $100 \mathrm{~cm}$, respectivamente.

Quanto ao "passo grande", observemos que, das medidas romanas antigas, conhecemos o passo simples, por vezes tomado como sendo equivalente a $0,74 \mathrm{~m}$ e noutras vezes, com a equivalência de $0,82 \mathrm{~m}$. Por seu lado, a chave é a medida da distância da ponta do dedo polegar até a ponta do dedo indicador; observamos seu uso em Minas Gerais e no Tocantins, com a equivalência máxima de $15 \mathrm{~cm}$. Ceres nos revela que tal medida também é utilizada em Goiás. Quando o seu informante lhe descreve o tamanho das ramas de mandioca usadas para o plantio, ele assume a equivalência de aproximadamente $10 \mathrm{~cm}$.

Em paralelo com a pesquisa, como proposta de extensão/intervenção da estagiária, o trabalho de Ceres considera não só os conceitos matemáticos curriculares e os envolvidos no cotidiano do produtor de mandiocas, mas também dá ênfase à Educação Ambiental. Ceres entende que o respeito à reserva legal nas propriedades rurais deve ser fruto de conscientização a efetuarse por meio da Educação Ambiental que pode ocorrer, inclusive, nas aulas de matemática. Contudo, a escola do assentamento faz parte de um amplo número de instituições nas quais as discussões sobre problemas ambientais ficam relegadas à disciplina de Ciências.

Assinala-se ainda que os professores não dispõem de material didático adequado à realidade específica da comunidade, que leve em consideração sua cultura e seus conhecimentos etnomatemáticos relativos, por exemplo, às medidas de comprimento. Na tentava de contribuir para mudar tal situação, Ceres e sua orientadora no estágio - a autora desse texto - têm-se dedicado à produção de sequências didáticas e de jogo pedagógico que possam fornecer subsídios para a inserção da Educação Ambiental nas aulas de matemática da escola do assentamento. Nos materiais pedagógicos que vêm sendo produzidos, tem sido possível abordar conteúdos tais como frações, porcentagem, cálculo de área e de perímetro de figuras planas, medidas de comprimento e de capacidade, dentre outras.

Por exemplo, no jogo de trilha criado no bojo do projeto de Ceres, uma das cartas do jogo anuncia: "Você decidiu fazer uma plantação em um lote que mede 8 hectares. A terra é uma área de cerrado e você deixou uma reserva legal de 1,6 hectares (20\%). Logo, não cumpriu a determinação que impõe uma reserva legal de 35\% para áreas de cerrado. Volte duas casas”. Noutra carta, é possível ler: "Para o plantio da mandioca (Manihot esculenta Crantz), também conhecida como macaxeira ou aipim, devemos escolher uma boa rama/caule. Uma rama de $80 \mathrm{~cm}(0,8 \mathrm{~m})$ 
pode ser dividida em no máximo quantas chaves? Ande a metade do número das casas encontradas como resposta".

Desse modo, tanto as sequências didáticas quanto o jogo têm permitido explorar múltiplos conteúdos matemáticos, associados a temas relevantes para a Educação do Campo e a Educação Ambiental. Assim, o trabalho alternativo pensado como uma forma para que Ceres - moradora da zona rural e com dificuldades de acesso à internet — pudesse dar cumprimento às atividades de estágio durante o período de isolamento social aponta a possibilidade de criação de espaços para a inserção de temáticas que têm encontrado lugar reduzido no currículo do curso.

\section{Considerações finais}

No texto, tomando como cenário mais amplo o isolamento social imposto pela COVID19 e as formulações teórico-práticas para a formação de professores e sobre o estágio supervisionado, vertemos nossas considerações para o curso de Licenciatura em Matemática do Campus do Araguaia, da UFMT. Observando que a exclusão digital é uma realidade vivida por estudantes do curso e que em 2020 a instituição aderiu ao ensino remoto emergencial, inquerimos sobre as possíveis contribuições da experiência na disciplina de Estágio Supervisionado III para reconfigurar as práticas a serem constituídas na licenciatura em matemática pós-pandemia. Dentre os projetos desenvolvidos pelos estagiários, destacamos o de Ceres, moradora de um assentamento rural do MST. Tal projeto expressa sua preocupação com a Educação do Campo e a Educação Ambiental a ser efetuada na sala de aula de matemática.

A partir daí, resgatamos a legislação que indica a necessidade de realização da Educação Ambiental em todos os níveis de ensino e, de modo especial, na formação de professores. Salientamos que vários cursos têm apresentado dificuldades na adoção de estratégias para que a Educação Ambiental se efetive. Destacamos que discussões sobre a Educação do Campo têm sido suprimidas. Nesse contexto, a estudante Ceres tem atuado contra o desrespeito à reserva legal, isto é, contra o descaso com relação à proteção das coberturas vegetais nativas. Em paralelo, na execução de seu projeto, ela tem buscado detectar e valorizar saberes matemáticos locais, etnomatemáticos, utilizados no assentamento rural.

Melo e Pimenta (2019) ressaltam que é papel da Universidade:

[...] propiciar a formação de um profissional preparado para enfrentar um mundo de mudanças e incertezas (IMBERNÓN, 2002), no qual é exigido o desenvolvimento de saberes docentes (específicos para o exercício da profissão), além de saberes relacionados à convivência humana (...). (p. 59) 
Aliando ao posicionamento acima descrito e compreendendo que professores e estudantes constituem agentes de mudança dos processos vigentes nos cursos de graduação, concluímos que os resultados da pesquisa-ação à qual nos dedicamos nos últimos meses do ano de 2020 podem contribuir para reconfigurar as práticas a serem constituídas nas licenciaturas em matemática póspandemia, ou no abrandamento da COVID-19. Isso ocorre na medida em que os resultados que obtivemos apontam a extensão universitária como uma opção concreta para a inserção da temática ambiental e para se desenvolver discussões afeitas à Educação do Campo em cursos de Licenciatura em Matemática que não tenham orientado seu currículo para a abordagem dessas temáticas; ou que o fizeram de forma incipiente.

As práticas aqui analisadas ocorreram no estágio supervisionado, mas cabe lembrar que o Plano Nacional de Educação - Lei nº 13.005/2014 - e a Resolução CNE n 7/2018 estabeleceram que, no mínimo, dez por cento do total de créditos curriculares exigidos para a graduação devem ser cumpridos em programas e projetos de extensão universitária (BRASIL, 2014). Entendemos que esse (novo) espaço deve ser voltado para a dialogicidade, para a compreensão e a ação em distintas realidades. Nos cursos de licenciatura, a chamada curricularização da extensão pode contribuir para que o professor reflita sobre o seu papel frente aos problemas sociais; por exemplo, com relação à ação predatória frente à natureza. Assim, a necessária inserção da Educação Ambiental nas licenciaturas e a discussão acerca do ensino para os campesinos podem ocorrer por meio da ocupação do espaço criado pela referida Lei; afinal, como apontou nosso estudo, a extensão universitária pode constituir-se como uma eficaz opção nesse sentido.

\section{Referências}

ANDRÉ, Marli. A pesquisa sobre formação de professores: contribuições à delimitação do campo. In: DALBEN, Ângela et al. (org.) Convergências e tensões no campo da formação e do trabalho docente. Belo Horizonte. Autêntica, 2010.

ARROYO, Miguel Gonzalez; CALDART, Roseli Salete; MOLINA, Mônica Castagna. Por uma educação do campo. $3^{\mathrm{a}}$ ed. Petrópolis: Vozes, 2008.

BALDIN, Nelma; LEAL, Amanda Carina e Silva. Ambientalização curricular do ensino superior na universidade da região de Joinville - UNIVILLE: os cursos de licenciatura e direito. Contexto \& Educação, v. 34, p. 52-71, 2019. Disponível em https://www.revistas.unijui.edu.br/index.php/contextoeducacao/article/view/6818. Acesso em 09 set. 2020.

BASTOS, Thais Basem Mendes Corrêa e BOSCARIOLI, Clodis. Os Professores do Ensino Básico e as Tecnologias Digitais: uma reflexão emergente e necessária em tempos de pandemia. 


\section{Dialogia}

COSTA, Wanderleya Nara Gonçalves. Vida e circunstâncias, estágio supervisionado na Licenciatura em Matemática e isolamento social: constituindo alternativas

SBC Horizontes. Porto Alegre, 2020.Disponível em:

http://horizontes.sbc.org.br/index.php/2020/04/22/professores-do-ensino-basico-e-astecnologias-digitais/ Acesso em 14 out. 2020.

BRASIL. Lei Federal 9.795/99 de 27 de abril de 1999. Dispõe sobre a educação ambiental, institui a Política Nacional de Educação Ambiental e dá outras providências. Diário Oficial da União. Brasília, DF, 27 abr. 1999. Disponível em:

http://www.planalto.gov.br/ccivil_03/LEIS/L9795.htm. Acesso em 10 set. 2020.

BRASIL. Resolução CNE/CP n ${ }^{\circ}$ 02, de 20 de dezembro de 2019. Define as Diretrizes

Curriculares Nacionais para a Formação Inicial de Professores para a Educação Básica e institui a Base Nacional Comum para a Formação Inicial de Professores da Educação Básica (BNCFormação). Ministério da Educação. Conselho Nacional de Educação. Conselho Pleno. Brasília: MEC, 2019.

BRASIL. Resolução n. 2, de 15 de junho de 2012. Estabelece as Diretrizes Curriculares Nacionais para a Educação Ambiental. Diário Oficial da União. Brasília, n. 116, seção 1, p. 70,18 jun. 2012. Disponível em: http://conferenciainfanto.mec.gov.br/images/conteudo/ivcnijma/diretrizes.pdf. 10 jul. 2020.

CARVALHO, Ramires Santos; COSTA, Alessandra David. Saberes docentes e o professor reflexivo: reflexão na prática escolar. Debates em Educaşão, v. 7, p. 156-167, 2015. Disponível em https://www.seer.ufal.br/index.php/debateseducacao/article/view/742. Acesso em 11 nov. 2020.

CORTES JUNIOR, Lailton Passos; FERNANDEZ, Carmen. A educação ambiental na formação de professores de química: estudo diagnóstico e representações sociais. Quím. Nova, São Paulo, v. 39, n. 6, p. 748-756, July 2016. Disponível em http://www.scielo.br/scielo.php?script=sci_arttext\&pid=S0100$40422016000600748 \& \operatorname{lng}=$ en\&nrm=iso. Acesso em 16 out. 2020. https://doi.org/10.5935/0100-4042.20160044.

COSTA, Wanderleya Nara Gonçalves. A constituição da identidade docente e o estágio em matemática. EDUCA - Revista Multidisciplinar em Educação, Porto Velho/RO, Vol.7, n.17, 2020. p. 579-598. Disponível em EDUCA - Revista Multidisciplinar em Educação. Acesso em 03 out. 2020. https://doi.org/10.26568/2359-2087.2020.5071.

D’AMBRÓSIO, U. Etnomatemática. Elo entre as tradições e a modernidade. $2^{a}$ Edição. Belo Horizonte: Autêntica, 2002. (Coleção Tendências em Educação Matemática).

DELORS, Jacques et al. Educação: um tesouro a descobrir. Relatório para a UNESCO da comissão internacional sobre educação para o século XXI (J. C. Eufrázio, Trad.). São Paulo: Cortez, 1998. Acesso: 09 jul. 2020. Disponível:

http://dhnet.org.br/dados/relatorios/a_pdf/r_unesco_educ_tesouro_descobrir.pdf.

DIONNE, Hugues. Pesquisa ação para o desenvolvimento local. Trad. Michael Thiollent. Brasília: Liber, 2007.

FORNASIER, Mateus de Oliveira; SCARANTTI, Danielli Scarantti. Internet no campo: direitos humanos e políticas públicas de inclusão digital. Revista Extraprensa, [S. l.], v. 10, n. 2, p. 133-152, 
2017. DOI: 10.11606/extraprensa2017.116050. Disponível em: http://www.revistas.usp.br/extraprensa/article/view/116050. Acesso em: 20 set. 2020

MELO, Geovana Ferreira; PIMENTA, Selma Garrido. Socialização profissional de docentes na universidade: contribuições teóricas para o debate. Revista Linhas. Florianópolis, v. 20, n. 43, p. 51-77, maio/ago. 2019. DOI: 10.5965/1984723820432019051 http://dx.doi.org/10.5965/1984723820432019051.

PIMENTA, Selma Garrido. Pesquisa e Formação de Professores: contextualização histórica e epistemológica de um projeto integrado. In: GUIMARÃES, Valter S. (org.). Formar para o mercado ou para a autonomia? Campinas: Papirus, 2006. p. 67-88.

PIMENTA, Selma Garrido; LIMA, Maria Socorro Lucena. Estágio e Docência. São Paulo: Cortez, 2004.

RIBEIRO, Gabriela Machado; MARIN, Elizara Carolina. Educação Física escolar: a ação pedagógica e sua legitimação enquanto prática social na Escola Itinerante do MST. Movimento, Porto Alegre, v. 15, n. 4, p. 63-82, out./dez. 2009. Disponível em https://seer.ufrgs.br/Movimento/article/view/6181/6939. Acesso em 19 nov.2020.

SILVA, Amanda Carina Leal; BALDIN, Nelma. Ambientalização curricular do ensino superior na universidade da região de Joinville - Univille: os cursos de licenciatura e direito. Contexto \& Educação, v. 34, p. 52-71, 2019. Disponível

em https://www.revistas.unijui.edu.br/index.php/contextoeducacao/article/view/6818/6011. Acesso em 16 out. 2020.

Recebido em: 25 out. 2020/ Aprovado em: 25 nov. 2020

\section{Cite como}

\section{(ABNT NBR 6023:2018)}

COSTA, Wanderleya Nara Gonçalves. Vida e circunstâncias, estágio supervisionado na Licenciatura em Matemática e isolamento social: constituindo alternativas. Dialogia, São Paulo, n. 36, p. 335-347, set./dez. 2020. Disponível em: https://doi.org/10.5585/dialogia.n36.18573.

\section{American Psychological Association (APA)}

Costa, W. N. G. Vida e circunstâncias, estágio supervisionado na Licenciatura em Matemática e isolamento social: constituindo alternativas. Dialogia, São Paulo, 36, p. 335-347. https://doi.org/10.5585/dialogia.n36.18573. 